OPEN ACCESS

Edited by:

Christel Hassler,

Université de Genève, Switzerland

Reviewed by:

Michal Kucera,

University of Bremen, Germany

Michaël Hermoso,

Sorbonne Universités, France

*Correspondence:

Silke Lischka

slischka@geomar.de

Specialty section:

This article was submitted to

Marine Biogeochemistry,

a section of the journal

Frontiers in Marine Science

Received: 26 April 2018 Accepted: 28 September 2018

Published: 24 October 2018

Citation:

Lischka S, Stange P and Riebesell U (2018) Response of Pelagic Calcifiers (Foraminifera, Thecosomata) to Ocean

Acidification During Oligotrophic and

Simulated Up-Welling Conditions in

the Subtropical North Atlantic Off Gran

Canaria. Front. Mar. Sci. 5:379

doi: 10.3389/fmars.2018.00379

\section{Response of Pelagic Calcifiers (Foraminifera, Thecosomata) to Ocean Acidification During Oligotrophic and Simulated Up-Welling Conditions in the Subtropical North Atlantic Off Gran Canaria}

\author{
Silke Lischka*, Paul Stange and Ulf Riebesell \\ GEOMAR Helmholtz Centre for Ocean Research Kiel, Biological Oceanography, Kiel, Germany
}

Planktonic Foraminifera and thecosome pteropods are major producers of calcite and aragonite in the ocean and play an important role for pelagic carbonate flux. The responses of planktonic foraminifers to ocean acidification $(\mathrm{OA})$ are variable among the species tested and so far do not allow for reliable conclusion. Thecosome pteropods respond with reduced calcification and shell dissolution to OA and are considered at high risk especially at high latitudes. The present investigation was part of a large-scale in situ mesocosm experiment in the oligotrophic waters of the eastern subtropical North Atlantic. Over 62 days, we measured the abundance and vertical flux of pelagic foraminifers and thecosome pteropods as part of a natural plankton community over a range of $O A$ scenarios. A bloom phase was initiated by the introduction of deep-water collected from approx. $650 \mathrm{~m}$ depth simulating a natural up-welling event. Foraminifers occurred throughout the entire experiment in both the water column and the sediment traps. Pteropods were present only in small numbers and disappeared after the first two weeks of the experiment. No significant $\mathrm{CO}_{2}$ related effects were observed for foraminifers, but cumulative sedimentary flux was reduced at the highest $\mathrm{CO}_{2}$ concentrations. This flux reduction was most likely accompanying an observed flux reduction of particulate organic matter (POM) so that less foraminifers were intercepted and transported downward.

Keywords: ocean acidification, pteropods, foraminifers, mesocosm experiment, oligotrophic ocean, subtropical, North Atlantic, export flux

\section{INTRODUCTION}

The global ocean absorbs yearly about $27 \%$ of the anthropogenically emitted $\mathrm{CO}_{2}$ (Rhein et al., 2013; Le Quéré et al., 2015) whereby the seawater chemistry is changed and the $\mathrm{pH}$, the carbonate ion concentration $\left[\mathrm{CO}_{3}{ }^{2-}\right]$ and the saturation states $(\Omega)$ of the calcium carbonates $\left(\mathrm{CaCO}_{3}\right)$ calcite (ca) and aragonite (ar) decline (Zeebe and Wolf-Gladrow, 2001). This phenomenon is termed ocean 
acidification (OA). Presently, the mean ocean surface $\mathrm{pH}$ ranges between 7.8 and 8.4 and models project a further decrease of 0.1-0.4 units by the end of this century (Ciais et al., 2013). $\mathrm{OA}$ has the potential to impact marine life on organismal and ecosystem levels (e.g., Wittmann and Pörtner, 2013; Dutkiewicz et al., 2015; Hammill et al., 2017; Riebesell et al., 2017). Calcifying organisms are particularly sensitive because shell and skeleton formation becomes increasingly difficult with decreasing calcium carbonate saturation states (Guinotte and Fabry, 2008; Doney et al., 2009; Kroeker et al., 2010, 2013). The ability of calcifiers to deal with $\mathrm{OA}$ conditions therefore critically depends on how much they are able to regulate intracellular $\mathrm{pH}$ during calcification (Stumpp et al., 2012). Foaminifers for example can elevate the $\mathrm{pH}$ at calcification site by one unit above seawater pH (Bentov et al., 2009; de Nooijer et al., 2009). $\mathrm{CaCO}_{3}$ saturation states are generally highest in the tropics and lowest at high latitudes, because $\mathrm{CO}_{2}$ solubility increases with decreasing temperature (Fabry et al., 2008). The higher $\mathrm{CO}_{2}$ solubility in cold water intensifies this process due to increased uptake from the atmosphere. In contrast, the warm surface waters of the tropics and subtropics will not become aragonite or calcite undersaturated over the range of $\mathrm{CO}_{2}$ concentrations projected for this century (Ciais et al., 2013), although in some upwelling regions shoaling aragonite saturation horizons intrude on the depth ranges of calcifying planktonic organisms (Feely et al., 2004).

The vertical and temporal distribution of planktonic foraminifers (Protozoa) is mainly controlled by sea surface temperature (SST), hydrography and phytoplankton biomass in the productive surface layers (Schiebel and Hemleben, 2000; Wilke et al., 2009). Similar relationships determine the occurrence of pteropods (metazoa, pelagic gastropods) (AlmogiLabin et al., 1988; Fischer et al., 1996). Planktonic foraminifers and euthecosomatous (shell-bering) pteropods are the major calcifiers among marine zooplankton (Fabry et al., 2008). Pelagic Foraminifera make their shells (or tests) of calcite, whereas pteropods produce shells of aragonite, a metastable form of $\mathrm{CaCO}_{3}$ that is $50 \%$ more soluble than calcite (Mucci, 1983). Both groups are wide-spread in the ocean and contribute significantly to particulate inorganic carbon (PIC) and they also contribute to particulate organic carbon (POC) flux to depth (Schiebel, 2002; Tsurumi et al., 2005; Wilke et al., 2009). On a global mean, 25\% of total calcite production of planktonic foraminifers sinks to the deep ocean sediment surface which is equivalent to about $32-80 \%$ of total calcite flux to the deep ocean (Schiebel, 2002). Pteropods are more patchily distributed and thus aragonite flux rates show a high temporal and regional variability, but occasionally they can dominate carbonate flux (Bathmann et al., 1991; Schiebel, 2002). The contribution of aragonite to the total calcium carbonate flux oceanwide was estimated to $\sim 12 \%$ (Berner and Honjo, 1981), but in some areas it can amount to $>50 \%$ of total $\mathrm{CaCO}_{3}$ flux (Lalli and Gilmer, 1989). The contribution of pteropods to global pelagic carbonate production is estimated to $20-42 \%$ (Bednaršek et al., 2012a).

Due to their aragonitic shell, thecosome pteropods are particularly threatened by OA because their shells dissolve easily when $\Omega_{\mathrm{ar}}$ is nearing 1 and calcification rates decline with decreasing $\Omega_{\mathrm{ar}}$ (Comeau et al., 2010a,b; Lischka et al., 2011; Bednaršek et al., 2012b, 2014). Also, their survival is affected by $\mathrm{pCO}_{2}$ and habitat suitability is declining where the occurrence of undersaturated water with respect to aragonite is increasing (Lischka et al., 2011; Bednaršek et al., 2014; Thabet et al., 2015). No true OA perturbation studies are currently available on planktonic foraminifera. Studies that are available do not allow for clear distinction of confounding factors (e.g., Lombard et al., 2010; Keul et al., 2013). For benthic foraminifers, lab experiments revealed a range of responses to $\mathrm{OA}$ that include positive and negative correlations with $\mathrm{pCO}_{2}$ depending on species (e.g., Schmidt et al., 2014). Survivorship of large benthic foraminifers for example was unaffected (McIntyre-Wressnig et al., 2013; Schmidt et al., 2014; Prazeres et al., 2018). Growth and calcification of benthic species increased in response to elevated $\mathrm{pCO}_{2}$ (Vogel and Uthicke, 2012), yet net calcification rates of the planktonic foraminifer Neogloboquadrina pachydermy decreased under low $\mathrm{pH}$ conditions and in combination with elevated temperature this effect was moderated. Survival was not affected at all (Manno et al., 2012). Field observations underline that there is no simple relationship between abundance and growth of planktonic foraminifers and environmental conditions (e.g., carbonate saturation, temperature, productivity, optimum growth conditions) with substantial interspecies- and intraspecies-specific variations (Gonzalez-Mora et al., 2008; Beer et al., 2010; Weinkauf et al., 2016). Shell weight of Globigerionoides ruber from the Arabian Sea for example could be related to anthropogenic induced OA scenarios but also to periods of different upwelling intensities (de Moel et al., 2009). Studies along natural $\mathrm{CO}_{2}$ gradients revealed that densities and diversity of benthic foraminifer assemblages declined sharply with increasing $\mathrm{pCO}_{2}$ at $\mathrm{pH}$ levels of $<7.9\left(>700 \mu \mathrm{atm} \mathrm{pCO}_{2}\right)$ (Dias et al., 2010; Uthicke et al., 2013). On the other hand, modern Globigerina bulloides from the Southern Ocean had $30-35 \%$ lower shell weights as compared to the underlying Holocene-aged sediments (Moy et al., 2009). This finding is consistent with Davis et al. (2017) who found in laboratory experiments with Globigerinoides bulloides calcification and oxygen consumption to decrease with declining $\mathrm{pH}$ conditions. It should be noted, however, that most of the species tested, especially the benthic ones, bear symbionts which may mitigate the response to $\mathrm{OA}$ by $\mathrm{CO}_{2}$-fertilization through the symbionts. With respect to the ability of organisms to cope with elevated $\mathrm{pCO}_{2}$ in the long run, insights from natural habitats may be more conclusive than results from short-term lab experiments can suggest (Vogel and Uthicke, 2012).

For pteropods, most of these studies were conducted in polar regions. In some areas of the Arctic Ocean aragonite undersaturation is starting already now and will continue to expand and intensify in the coming decades. In tropical regions, $\Omega_{\mathrm{ar}}$ will stay well above 1 even beyond the end of this century and thus, OA may affect calcification rates but probably not cause shell dissolution in these regions. For foraminifers, IPCC projections for tropical regions for the second half of this century correspond with $\mathrm{pH}$ ranges for which drastic decrease of densities and diversity of benthic foraminifers have been described (Ciais et al., 2013; Uthicke et al., 2013). 
One of the most pressing questions in OA research is, how OA effects described for single species play out at the community level with respect to species abundance and diversity, trophic interactions, and elemental cycling, including the vertical flux of carbon and carbonate. In this regard, large-scale in situ mesocosm experiments enclosing natural plankton communities provide a powerful approach to gain a more realistic insight into how OA effects on individual organisms translate to the community level. Recent mesocosm experiments performed in the Baltic Sea, the Skagerrak, and the Mediterranean Sea suggest OA effects on plankton communities may be stimulated during times of low inorganic nutrient concentrations (Paul et al., 2015; Sala et al., 2016; Bach, et al., 2016). Possible OA effects on plankton communities in the oligotrophic waters of the North Atlantic subtropical gyres have not yet been studied. The oligotrophic waters around the Canary Islands in the subtropical North Atlantic are characterized by low nutrient concentrations during most of the year (Arístegui et al., 1997), but regular upwelling events of deep water through island-induced eddy formation as well as upwelling filaments reaching out to the Canary Islands from the West-African coast provide for frequent nutrient pulses and accompanying bloom situations (Arístegui et al., 2001; Sangra et al., 2009).

In this study, we intended to test how possible OA responses of the plankton community may change during a temporary shift from oligotrophic to eutrophic conditions. To simulate this, we conducted a 9-week $\mathrm{CO}_{2}$-manipulated mesocosm experiment to which we added natural nutrient-rich deep-water collected in the field midway of the experiment to mimic a natural upwelling event (Taucher et al., 2017). As part of the Gran Canaria KOSMOS study, described in detail in Taucher et al. (2017), this paper focusses on possible OA effects on the occurrence and succession of pelagic calcifiers (thecosome pteropods, heteropods, planktonic foraminifers) in the water column of the mesocosms and on their vertical flux to the sediment traps. Establishing OA conditions through the addition of different amounts of $\mathrm{CO}_{2}$-enriched seawater to the mesocosms assured a realistic OA scenario. Thus, this study provided the unique opportunity to investigate for the first time the impact of $\mathrm{OA}$ on pelagic calcifiers on ecosystem-level.

\section{METHODS}

\subsection{Mesocosm Set-Up}

To investigate OA effects on a natural plankton community in the oligotrophic subtropical North Atlantic, nine off-shore pelagic mesocosms (KOSMOS: "Kiel Off-Shore Mesocosms for Ocean Simulations") were deployed and moored on 23 September 2014 in the northern Gando Bay at $27^{\circ} 55^{\prime} 41^{\prime \prime} \mathrm{N}, 15^{\circ} 21^{\prime} 55^{\prime \prime} \mathrm{W}$ (Gran Canaria). Approximate bottom depth at the mooring site was $\sim 20-25 \mathrm{~m}$. The bags of the mesocosms extended down to $13 \mathrm{~m}$ and were closed with a $2 \mathrm{~m}$ long conical sediment trap that allows for regular collection of settled material via a vacuum pump system. After deployment, the bags were initially kept open and submerged to $\sim 1 \mathrm{~m}$ below the ocean surface so that a free exchange with the surrounding plankton community and water was ensured for 4 days. During this time, the upper and lower end of the bags were covered with a $3 \mathrm{~mm}$ mesh to exclude larger plankton (Cnidaria) and fish. The experiment started on 27 September 2014, when these nets were removed and simultaneously the sediment traps were attached to the bottom and the mesocosm bags pulled up to above the ocean surface to isolate the enclosed plankton community from the surrounding water masses. The water volumes right before deepwater addition ranged between 31.57 and $37.75 \mathrm{~m}^{3}$ (Taucher et al., 2017). The first $\mathrm{CO}_{2}$ addition was performed on 1 October and is denoted day $0(\mathrm{t} 0)$, i.e., the start of the experiment was 4 days prior to the first $\mathrm{CO}_{2}$ manipulation and is denoted day $-4(\mathrm{t}-$ 4). The experiment lasted for 62 days with the last sampling day on 27 November (t57). To simulate a natural upwelling event, on t 24 we injected deep water in each of the mesocosms. For this $20 \%$ of the enclosed water was substituted with deep water collected at $650 \mathrm{~m}$ depth to simulate the input of comparable amounts of inorganic nutrients as observed during natural upwelling events in this region (Arístegui et al., 1997; Neuer et al., 2007). Deepwater volumes added to the mesocosms ranged between 7.50 and $8.95 \mathrm{~m}^{3}$ (Taucher et al., 2017).

OA was simulated by adding different amounts of $\mathrm{CO}_{2}$ saturated seawater to seven of the nine mesocosms according to Riebesell et al. (2013) to set up an initial $\mathrm{pCO}_{2}$ gradient from ambient levels of $\sim 400 \mu$ atm to a maximum concentration of $\sim 1,480 \mu \mathrm{atm}$ in the highest $\mathrm{CO}_{2}$ treatment. A detailed description of the $\mathrm{CO}_{2}$ manipulations is given in Taucher et al. (2017). In short, about 1,500 L natural pre-filtered seawater was collected from Melenara Bay using a pipe and bubbled with pure $\mathrm{CO}_{2}$ gas until saturation. Before filling the $\mathrm{CO}_{2}$-saturated seawater in $20 \mathrm{~L}$ containers and subsequent boat-transport to the mesocosms, it was filtered again $(20 \mu \mathrm{m})$. The different amounts of $\mathrm{CO}_{2}$-saturated seawater were added to the mesocosms with a special distribution device that assures uniform distribution within a radius of $\sim 1 \mathrm{~m}$ (Riebesell et al., 2013). The volume of $\mathrm{CO}_{2}$-saturated seawater needed to reach target $\mathrm{pCO}_{2}$ levels in the mesocosms was calculated from measured DIC and TA concentrations. Determination of the carbonate system was part of the regular sampling effort carried out every second day. $\mathrm{CO}_{2}$ additions were done stepwise over 7 days to allow for gradual acclimation of the plankton community, and thus final starting conditions were reached on t6. To compensate for a $\mathrm{CO}_{2}$ loss through air-sea gas exchange, two further $\mathrm{CO}_{2}$ manipulations were conducted on $\mathrm{t} 21$ prior to the deep-water addition (oligotrophic phase) and on t38 during the postbloom phase. The $\mathrm{CO}_{2}$ gradient was chosen according to IPCC scenarios projected for this century. M1 and M9 served as controls and were not $\mathrm{CO}_{2}$ manipulated. Manipulations resulted in average $\mathrm{pCO}_{2}$ values over the experiment duration $(\mathrm{t} 1-\mathrm{t} 55)$ ranging from $352 \mu \mathrm{atm}$ to $1,025 \mu \mathrm{atm}$ (Table 1). Unfortunately, M6 was lost on 127 due to strong currents (Taucher et al., 2017).

\subsection{Sampling and Enumeration of Calcifiers in the Water Column}

Mesozooplankton net sampling was conducted vertically with an Apstein net of $55 \mu \mathrm{m}$ mesh size and $17 \mathrm{~cm}$ diameter aperture. 
TABLE 1 | Mesocosm set-up with mean $\mathrm{pCO}_{2}$ [ $\mu$ atm], mean $\mathrm{pH}_{\mathrm{T}}$ (total scale), mean carbonate ion concentration [CO ${ }_{3}{ }^{2-}$ ], mean $\Omega_{\mathrm{calcite}}\left(\Omega_{\mathrm{Ca}}\right)$, and mean $\Omega_{\text {aragonite }}$ $\left(\Omega_{\mathrm{ar}}\right)$ values, averaged over the whole experimental duration (t1-t55; except for M6).

\begin{tabular}{|c|c|c|c|c|c|c|c|}
\hline Mesocosm & Symbol & $\mathrm{pCO}_{2}$ & $\mathrm{pH}_{\mathrm{T}}$ & {$\left[\mathrm{CO}_{3}{ }^{2-}\right]$} & $\Omega_{\mathrm{ca}}$ & $\Omega_{\mathrm{ar}}$ & Note \\
\hline M1 & & $369(43)$ & $8.09(0.04)$ & $248(17.5)$ & $5.8(0.4)$ & $3.8(0.26)$ & Control \\
\hline M9 & & $352(60)$ & $8.11(0.06)$ & 260 (26.5) & $6.11(0.62)$ & $4.02(0.40)$ & Control \\
\hline M5 & & $448(67)$ & $8.02(0.06)$ & 221 (22.9) & $5.19(0.54)$ & $3.41(0.35)$ & \\
\hline M3 & & $563(86)$ & $7.94(0.06)$ & $190(21)$ & $4.47(0.49)$ & $2.94(0.32)$ & \\
\hline M7 & & $668(121)$ & $7.78(0.07)$ & $170(25)$ & $3.99(0.59)$ & $2.63(0.39)$ & \\
\hline M4 & & 716 (136) & $7.86(0.08)$ & 162 (23.6) & $3.8(0.56)$ & $2.5(0.37)$ & \\
\hline \multirow[t]{2}{*}{ M6 } & & 970 (126) & $7.74(0.05)$ & 129 (14.5) & $3.03(0.34)$ & $2.0(0.23)$ & Mean t1-t26 \\
\hline & & & & & & & lost on t27 \\
\hline M2 & & 887 (206) & 7.78 (0.09) & $140(25.7)$ & $3.29(0.6)$ & $2.16(0.4)$ & \\
\hline M8 & & 1025 (230) & $7.72(0.09)$ & 125 (22.1) & $2.93(0.52)$ & $1.93(0.34)$ & \\
\hline Atlantic & & $399(15)$ & $8.06(0.01)$ & 227 (4.8) & $5.37(0.11)$ & $3.53(0.08)$ & \\
\hline
\end{tabular}

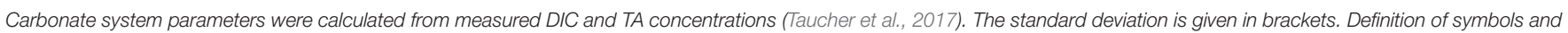
color-code used in the figures.

All mesocosms were sampled evenly, i.e., the same amount of net hauls was taken from all mesocosms on each sampling event. The first net hauls were taken on $\mathrm{t}-3$, the day after mesocosm closure. Beginning on $\mathrm{t} 1$, further net hauls were done on a regular 8 days basis. However, due to adverse weather conditions, sampling on t49 had to be shifted to 50 resulting in a 9 days interval between $\mathrm{t} 41$ and $\mathrm{t} 50$. Additional net samples were also taken at experiment closure (t56). Sampling depth was $13 \mathrm{~m}$ to avoid resuspension of material from the sediment trap zone resulting in $295 \mathrm{~L}$ of total filtered water volume. Net hauls were always done between 14:00 and 16:00 CET. After retrieval of the net, zooplankton was quantitatively rinsed into sample bottles with filtered seawater and stored in cooled containers to prevent them from heating. Samples where brought back to PLOCAN (Platforma Oceánica de Canarias) were the research campaign was hosted (Taucher et al., 2017). Back in the PLOCAN laboratories, samples were immediately preserved in $70 \%$ ethanol.

Calcifiers [Thecosomata, Pterotracheoidea (formerly heteropods), and Foraminifera] were counted and identified under a WILD M3B stereomicroscope assuming 100\% filtering efficiency of the net. Abundances were calculated as individuals $\mathrm{m}^{-3}$. Foraminifers had a strong tendency to clump together with their spines and therefore accurate enumeration was not possible without prior sorting of the individuals and likewise it was not possible to assure accurate splitting to estimate abundances from subsamples. Therefore, all calcifiers were counted and identified from the whole sample after species identification and abundance determination of the bulk zooplankton was completed (AlgueróMuñiz et al. submitted). As identification and enumeration of all foraminifer specimen was not possible on the species level due to their small size, the species inventory was determined on some representative specimen only under higher magnification on a Keyence microscope (model number of microscope: VH-Z250R, model number of computer: VHX-700FD) with the help of Dr. N. Keul at Kiel University, but enumerations were done on family level (Globigerinidae). The same approach was applied to the sediment trap samples.

\subsection{Sampling and Enumeration of Calcifiers in the Sediment Trap Material}

The sediment traps were emptied every 2 days using a manual vaccum pump to collect the settled material via a silicon tube connected to the collection cylinder of the sediment trap (Riebesell et al., 2013; Boxhammer et al., 2015). Pteropods, heteropods, and foraminifers were counted prior to processing of these samples for quantification and characterization of bulk particulate matter. Initially, we tried to count representatives of the three groups from the whole sediment sample. However, from t5 onwards, samples became too voluminous and foraminifers too abundant that regular every other day counting became too laborious and time-consuming. Therefore, enumeration of foraminifers had to be restricted to $50 \mathrm{ml}$ subsamples from $\mathrm{t} 5$ onwards. Pteropods and heteropods, however, were much less abundant and were not found representatively in subsamples, and hence were continually counted from the complete sample until $\mathrm{t} 35$. On that day, sedimentation had increased even stronger due to enhanced production in the water column in response to the deep-water addition on t 24 and it was no longer possible to enumerate pteropods and heteropods from the complete sediment trap samples. Thus, from $\mathrm{t} 35$ onwards, only the $50 \mathrm{ml}$ subsamples were checked for the occurrence of calcifiers.

\subsection{Statistics}

We performed statistical analyses on the abundance of planktonic Foraminifera (all belong to the family Globigerinidae) in the water column and on the flux of Globigerinidae and the sexual stage of Orbulina universa to the sediment traps. GLM (generalized linear mixed models) or GAMM (generalized additive mixed model) with a Gaussian distribution were used to test whether $\mathrm{pCO}_{2}$ had an effect on the temporal development of abundances. "Mesocosm" was included as random intercept. In case of GAMM a smoother on experiment day was included. $\mathrm{pCO}_{2}$ was used as continuous explanatory variable for each $t$-day to account for the change over time due to biological activity. We log-transformed flux data of Globigerinidae, because 
preceding GLM models suggested significance for $\mathrm{CO}_{2}$ but model validation showed strong variance heterogeneity especially due to the factor experiment day that could not be adequately captured by different variance structures tested. M6 was excluded from all analyses because it was lost on $\mathrm{t} 26 \mathrm{t}$ - 3 data were excluded from analyses of water column data to assure equally spaced data. All analyses were carried out with $\mathrm{R}$ using the package nlme, $\mathrm{mgcv}$, Hmisc and MASS. All plots were done in ggplot (R Core Team, 2013).

Pelagic mollusks occurred only very shortly during the first days of the experiment, both in the water column and sediment traps. In the water column, the spherical stage of Orbulina universa was only found on 19 . Thus, sampling frequency was comparatively low for these groups and, therefore, we did not do any statistical analyzes on the temporal trends in the different mesocosms.

\section{RESULTS}

\subsection{Percent Contribution of Calcifiers to the Mesozooplankton Community in the Water Column}

The abundance of pelagic calcifiers in the mesocosms was generally low throughout the study. Among the three groups of calcifying zooplankton, foraminifers were most numerous. Thecosome pteropods and heteropods (Pterotracheidae) were present only during the first days of the experiment and were virtually absent from $\mathrm{t} 9$ onwards. Highest contributions of pteropods were $1.7 \%$ (M6, t9) and of heteropods $0.7 \%$ $(\mathrm{M} 8, \mathrm{t} 1)$ of the total mesozooplankton abundance (data not shown). Foraminifers were present during the whole study and contributed between 0.2 and $11.3 \%$ to the total mesozooplankton abundance with some exeptional peaks in M7 on $\mathrm{t} 9$, in M8 on $\mathrm{t} 33$, and in M2 on $\mathrm{t} 50$. In the surrounding Atlantic water, pteropods were always found during the study period $(0.7-6 \%)$ with a contribution peak on $\mathrm{t} 25$ but heteropods were only occasionally identified with very low contributions (max. $0.4 \%)$. As in the mesocosms, foraminifers occurred continually in the Atlantic but had somewhat lower contributions as in the mesocosms (1-6\%). Representatives of both groups were mostly smaller than $200 \mu \mathrm{m}$, many of them even smaller than $100 \mu \mathrm{m}$ in size. Only very few larger pteropods (older stage of Creseis sp.) were found.

\subsection{Temporal Dynamics of Calcifiers}

\subsubsection{Water Column}

\subsubsection{Pteropoda and Heteropoda}

Abundances of thecosome pteropods in the mesocosms varied between 0 and 86 ind. $\mathrm{m}^{-3}$ and of heteropods between 0 and 32 ind. $\mathrm{m}^{-3}$ (Figures 1A,B). Compared to the mesocosms, numbers of pteropods in the surrounding Atlantic water were higher (18157 ind. $\left.\mathrm{m}^{-3}\right)$, and those of heteropods lower $\left(0-11\right.$ ind. $\left.\mathrm{m}^{-3}\right)$. In the mesocosms, both groups had abundance peaks during the first days $(\mathrm{t}-3, \mathrm{t} 1)$. As mentioned above already, pteropods and heteropods almost completely disappeared after t9/t17 in the mesocosms. Deep-water addition on $\mathrm{t} 24$ did not have an obvious effect on the occurrence of pteropods and heteropods in the water column. Abundances showed no trend with the $\mathrm{CO}_{2}$ concentration over time.

\subsubsection{Dominant pteropod and heteropod species/genus}

Most pteropod specimen found were Heliconoides inflatus with a maximum abundance of 86 ind. $\mathrm{m}^{-3}$. Occasionally, specimen of Limacina trochiformis ( $\max .4$ ind. $\mathrm{m}^{-3}$ ) and embryonal stages of some cavolinid thecosomes were found. Cavolinids most likely belonged to the genus Creseis sp. or Styliola sp. and reached maximum numbers of 61 ind. $\mathrm{m}^{-3}$ (data not shown). Heteropods identified in the samples belonged exclusively to the family Atlantidae (genus Atlanta) and the individuals found were all juvenile stages. In the surrounding Atlantic water, Heliconoides inflatus was present during the study period (18-157 ind $\mathrm{m}^{-3}$ ). L. trochiformis was not found, Creseis sp. and Styliola sp. as well as heteropods occurred only sporadically at low numbers (max. 4 and 11 ind. $\mathrm{m}^{-3}$, respectively).

\subsubsection{Dominant foraminiferan species/groups}

Of the planktonic foraminiferans (family Globigerinidae), the most abundant species that we identified were Globigerinoides ruber, Globigerina bulloides, Globigerinella siphonifera, and Orbulina universa (Figure 2A). The abundances of Globigerinidae ranged between 18 and 610 ind. $\mathrm{m}^{-3}$ (Atlantic: 25-103 ind. $\mathrm{m}^{-3}$ ). Temporarily, we found the sexual stage of O. universa in the mesocosms with peak abundances of 68 ind. $\mathrm{m}^{-3}$ on $\mathrm{t} 9$, but we did not find it in the net samples taken in the surrounding Atlantic water (Figure 2B). Occasionally, we also found a few specimen of the planktonic Globorotalia but these were too rare to analyze quantitatively. We also occasionally found many specimen of the benthic Tretomphalus with floating chambers in the net samples. These were, despite their abundance, not considered in the analysis, because they are not part of the normal pelagic community. Most likely, the mesocosms acted as artificial substrate for these benthic foraminifer species and reproduction may have been stimulated by nutrient fertilization after the deep-water addition. However, as mentioned already, they are not part of the pelagic community and therefore are not further considered here.

Abundances of Globigerinidae were not significantly affected by $\mathrm{CO}_{2}$ (GAMM, $p=0.39$ ) over time.

\subsubsection{Sediment Trap}

\subsubsection{Pteropoda and Heteropoda}

Peak occurrence of pelagic mollusks in the sediment traps was around t5 shortly after their abundance peak in the water column (Figures 1C,D) with a maximum time delay between peak abundance in the water column and in the sediment traps of 4 days. Sedimentation peaks of pteropods and heteropods were highest in M3, M4, and M5. A small increase in flux of both groups, pteropods and heteropods, in M1, M9, and M5 followed on t19. After that pelagic mollusks were absent, both in the sediment traps and the water column. Strikingly though, the total flux differed considerably from the abundance of pelagic mollusks in the water column (Figures 1E, F). This flux deficit is most likely due to the difficulty to find remains of these fragile organisms in the sediment traps. 

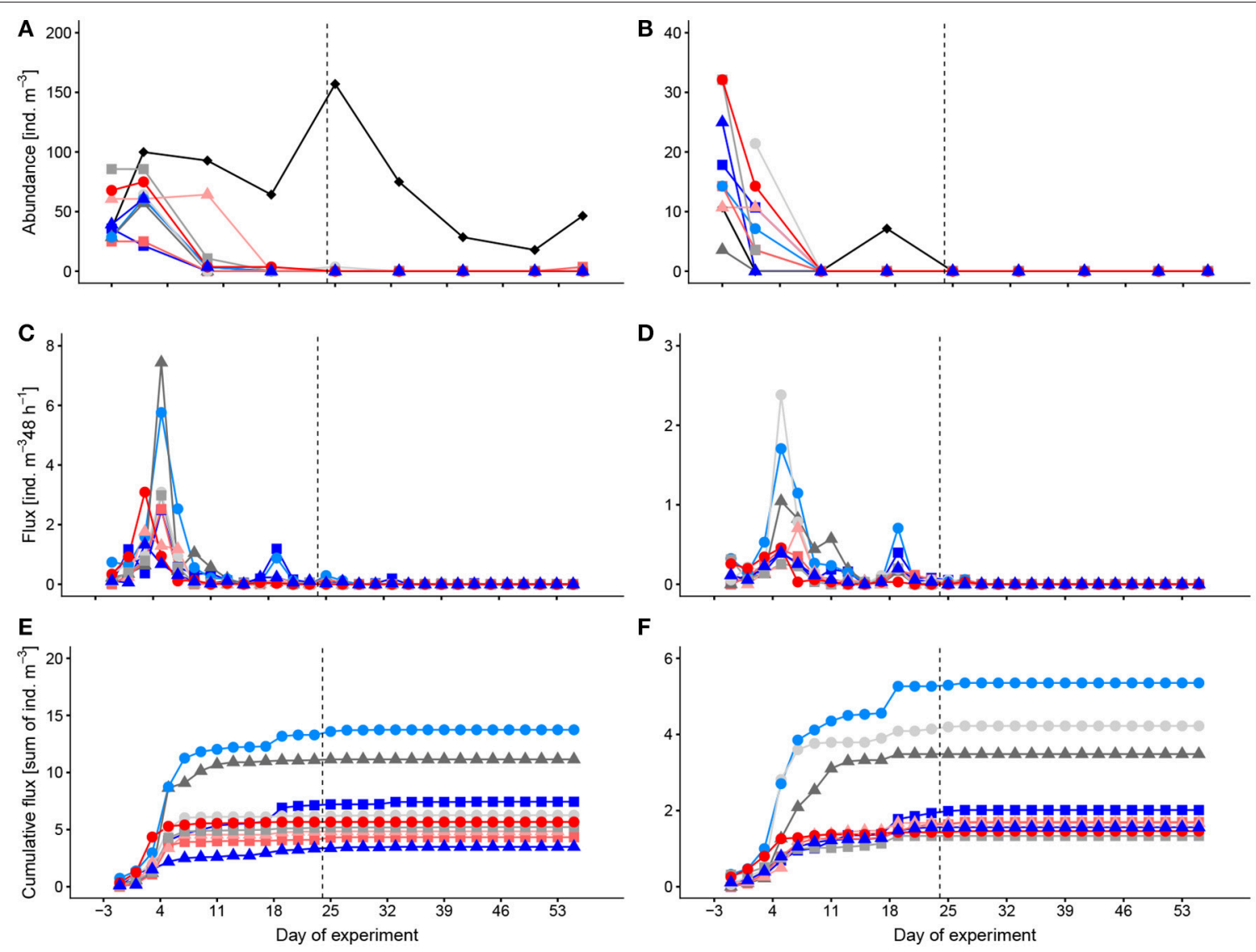

FIGURE 1 | Temporal development of standing stocks and flux to the sediment traps of thecosome Pteropoda (A,C,E) and Heteropoda (B,D,F). (A,B) abundances in the water column, (C,D) flux to the sediment trap per $48 \mathrm{~h}, \mathbf{( E , F )}$ cumulative flux to the sediment trap. Colors and symbols are described in Table 1. Dashed line indicates the time of deep-water addition. Note different scales.

\subsubsection{Foraminifera, Globigerinidae}

The main flux of Globigerinidae and of the spherical stage of Orbulina universa was around t9-t15 only shortly after their main peaks in the water column ( $\mathrm{t} 1$, $\mathrm{t}$; ; Figures $2 \mathrm{C}-\mathrm{F})$. The spherical stage of $O$. universa occurred in the sediments of most mesocosms [especially in M4, M8, and M2, (Figures 2D, F)] at low numbers also during the remainder of the experiment, indicating that net sampling failed to collect this stage in the water column after t9 (Figure 2B). The occurrence of the spherical stage of $O$. universa more or less throughout the experiment points to ongoing reproduction that likely was continuous. Reproduction and development is also indicated by comparing the abundance of Globigerinidae in the water column with the cumulative flux that the standing stock in the water column is continuously replenished.

The cumulative flux of Globigerinidae on the last sampling day (t55) is shown in Figure 3. The flux was lowest in one of the control mesocosms (M1, 361 ind. $\mathrm{m}^{-3} 48 \mathrm{~h}^{-1}$ ) and the two high $\mathrm{CO}_{2}$ mesocosms (M2, M8, 321 and 343 ind. $\mathrm{m}^{-3} 48$ $\mathrm{h}^{-1}$, respectively). The trend of the data resembles an optimum curve with highest flux at mid $\mathrm{CO}_{2}$ levels. Interestingly, a similar trend was not found in the water column. GAMM on the flux of Globigerinidae revealed no significant effect of $\mathrm{pCO}_{2}(p=0.05)$.
Also the flux of the sexual stage of Orbulina universa was not impacted by $\mathrm{CO}_{2}$ concentration (GLM, $p=0.84$ ).

\section{DISCUSSION}

\subsection{Pteropods and Heteropods \\ 4.1.1. General Considerations}

The occurrence of pteropods and heteropods in the mesocosms was only low and too short to allow for any sound conclusion on possible $\mathrm{CO}_{2}$ effects. Therefore, we restrict the discussion to some general considerations of what might have caused the quick disappearance of pelagic gastropods in the mesocosms in this particular study. Pteropods vanished in the mesocosms soon after the experiment had started, whereas they occurred continuously in the surrounding Atlantic water during the entire study. Also heteropods did not occur in the mesocosms for very long but they were also rare in the outside Atlantic. Survival of pteropods in our previous mesocosm experiments was variable and it is difficult to explain what causes success or failure. In general, pteropods are very delicate against captivity and until now cannot really be cultivated over an entire reproductive cycle (Howes et al., 2014). The most likely explanation for their quick disappearance is entrapment in the sediment traps in the course 

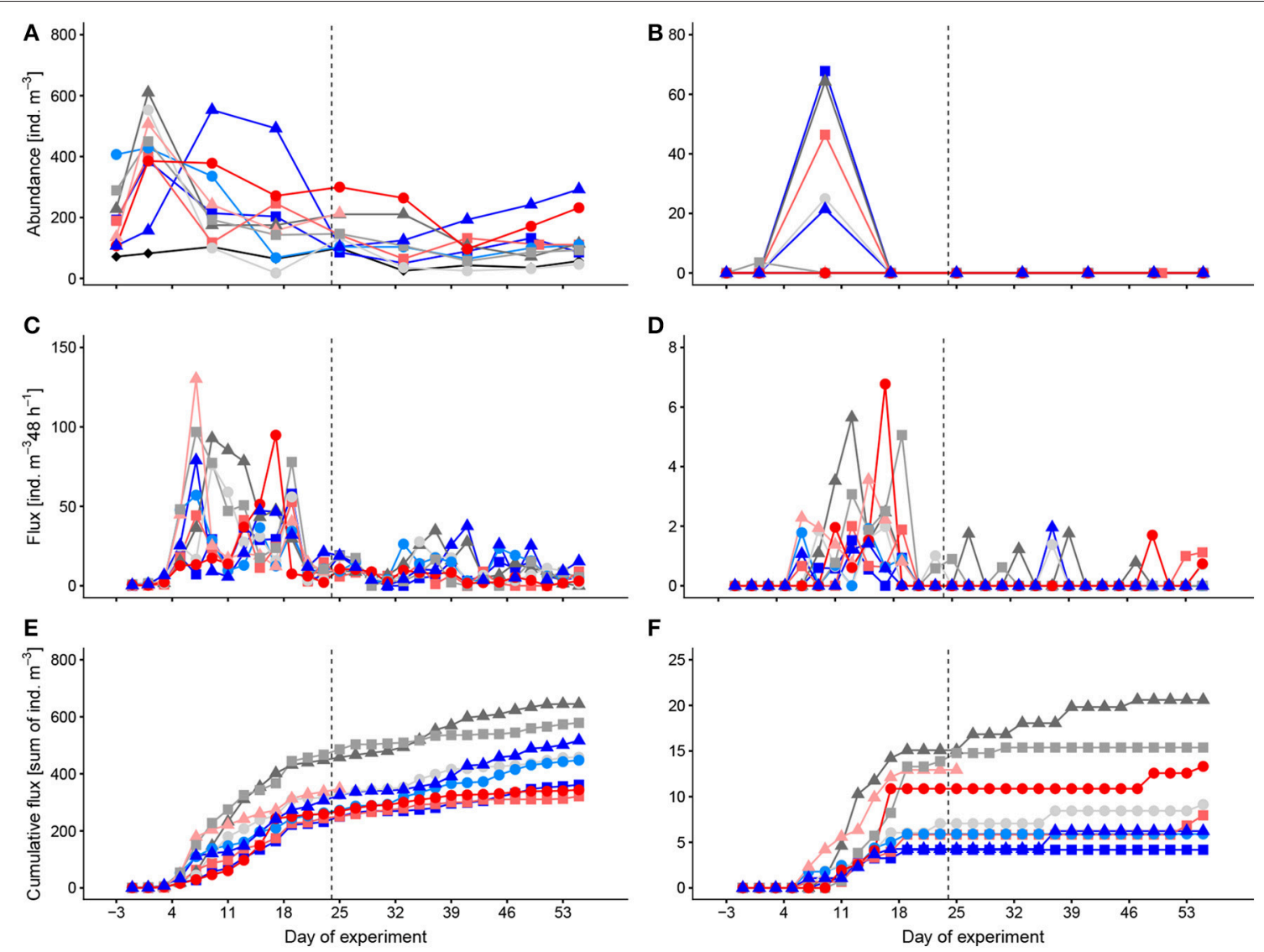

FIGURE 2 | Temporal development of standing stocks and flux to the sediment traps of Globigerinidae (A,C,E) and the sexual stage of Orbulina universa (B,D,F). $(\mathbf{A}, \mathbf{B})$ abundances in the water column, (C,D) flux to the sediment trap per $48 \mathrm{~h}, \mathbf{( E , F )}$ cumulative flux to the sediment trap. Colors and symbols are described in Table 1. Dashed line indicates the time of deep-water addition. Note different scales.

of their natural vertical migration. Heliconoides inflatus, the most dominant pteropod species in our experiment, performs diurnal vertical migrations in the upper $300 \mathrm{~m}$ (Bé and Gilmer, 1977). To descend pteropods can either rapidly sink down through a retraction of the wings into the shell or swim down. Rapid sinking is also used as escape reaction that can be easily initiated (Tsurumi et al., 2005) when accidentally bouncing against the mesocosm bags. Either way, the negative buoyancy of pteropods facilitates rapid sinking (Lalli and Gilmer, 1989), and in our study they may have accidentally fallen into the sediment trap of the mesocosm, where they entangled with the sedimented material and eventually died. Also in the mesocosm study performed in the Arctic, adult Limacina helicina vanished from the water column within a week most likely because they accumulated and died in the sediment traps (Niehoff et al., 2013). In contrast, all stages (veligers to adults) of the smaller North Atlantic species Limacina retroversa survived well throughout a 40 day long mesocosm experiment in the Norwegian Raunefjord conducted in 2011 (Howes et al., 2014, J. Büdenbender and U. Riebesell unpublished). During another mesocosm study in Raunefjord in 2015, however, L. retroversa early developmental stages (veligers, juveniles) occurred during the full duration of the experiment (45 days), but adult specimen were mainly found during the first days and were extremely rare after that (Lischka et al. unpublished). Given that Limacina spp. also migrate vertically, some favoring factor(s) must have contributed to their survival in the Bergen experiments in contrast to the Gran Canaria experiment. Reasons could be for example lower loss to the sediment traps due to less pronounced vertical migration behavior because of the longer day length at Raunefjord compared to the Canary region. However, the same explanation cannot hold for the Arctic study. Thus, so far no consistent picture emerges to explain loss or upkeep of pteropods in the mesocosms. In general, OA has the potential to affect standing stocks of pteropods negatively and to lower their calcification and, thus their contribution to the vertical flux of aragonite and calcite.

\subsection{Planktonic Foraminifers 4.2.1. Sepcies Inventory and Habitat Conditions in the Mesocosms}

Mesocosms cannot provide optimal living conditions for planktonic foraminifera because they have characteristic depth habitats that can differ considerably between species, (Hull et al., 2011; Rebotim et al., 2017) and they migrate vertically during their life cycles. (Hemleben et al., 1989; Bijma et al., 1990). Accordingly, they can be found primarily in open 


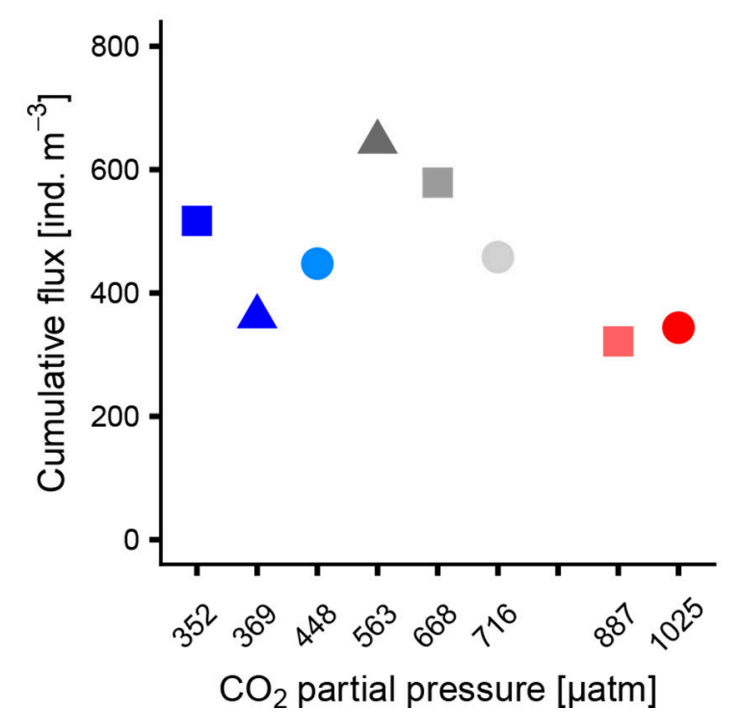

FIGURE 3 | Cumulative flux of Globigerinidae to the sediment traps on t55 (last sampling day) as a function of $\mathrm{pCO}_{2}$ averaged over the whole experiment duration.

waters (Rebotim et al., 2017). Thus, their natural vertical living range exceeds mesocosm depth and it is likely, that specimen enclosed in the mesocosms were advected into Gando Bay. These ecologic characteristics likely impacted on the flux observed to the sediment traps. The average living depth of the species enclosed in the mesocosms varies between 40 and 60 $\mathrm{m}$ for Globigerionoides ruber, around $80 \mathrm{~m}$ for Globigerinella siphonifera and Orbulina universa and $100 \mathrm{~m}$ for Globigerina bulloides (Wilke et al., 2009; Rebotim et al., 2017). The vast majority of export flux of planktonic foraminifera is generated below $100 \mathrm{~m}$ depth and consists mostly of empty adult specimen (Erez and Honjo, 1981). Thus, considering vertical movements related to the species' life cycles and their preferred living depths, it is likely that not only dead shells were collected in the mesocosm sediment traps but that also living (juvenile) specimen were passively intercepted not able to leave again and continue growing. This process may have dominated flux of these protozoans in the mesocosms and depleted water column stocks over time. We frequently counted individuals of different size in the sediment trap samples supporting this assumption. However, this is a general problem for vertically migrating zooplankton kept in closed systems that also applied equally to all mesocosms in our experiment. It probably generated an off-set to natural flux but shouldn't impede observe a general $\mathrm{CO}_{2}$ impact across our set-up.

Globigerinidae species enclosed in the mesocosms are typical for the Canary Island region and the subtropical eastern North Atlantic. Also reported numbers of Globigerinidae in the winter season are in the same range of what we found though they were somewhat higher in the mesocosms (Wilke et al., 2009; Rebotim et al., 2017). Wilke et al. for example indicate concentrations of Globigerinidae of up to 300 individuals $\mathrm{m}^{-3}$, while Rebotim et al. found densities of around $80-100 \mathrm{~m}^{-3}$. After some initial high values of about 600 individuals $\mathrm{m}^{-3}$, densities in the mesocosms stayed quite stable between about $100-200 \mathrm{~m}^{-3}$. These higher densities in the mesocosms are most likely due to the small mesh size used in our study $(55 \mu \mathrm{m})$ compared to $\geqslant 100 \mu \mathrm{m}$ meshes used in the field studies. Moreover these studies only considered individuals larger than $100 \mu \mathrm{m}$ whereas we counted all specimen found independent of size. However, when considering particular species, Orbulina universa had peak numbers (on t9) that were $\sim 30$ times higher than maximum densities reported by Rebotim and co-workers. These numbers bargained for the sexual stage of O. universa that is very easy to identify, i.e., we can exclude false identification. An overestimation of the filtered volume and calculated densities is unlikely since the lack of currents in the mesocosms allowed for more or less strictly vertical net hauls. Possibly it could be an artifact of the rather small volume filtered and patchy distribution in the mesocosm. As such high numbers were only found at the beginning of the experiment, another possible explanation could be some small scale eddies occurring prior mesocosm closure leading to short-term concentrations of pre-adult specimen that were then enclosed in the mesocosms. Lack of potential predators such as pelagic fish may be another reason enabling such high densities.

\subsubsection{Succession and Flux of Globigerinidae}

Foraminifers thrived well and reproduced in the mesocosms throughout the experiment. The most obvious evidence for most likely unsynchronized reproduction is the continuous occurrence of the spherical stage of Orbulina universa in the sediment traps more or less throughout the experiment. Constant replinishment is also suggested from the fact, that flux did not lead to deplete conditions in the water column despite we have to assume that also juvenile living specimen were passively caught in the traps as mentioned above. We exclude the possibility that the observed continuous flux was not due to reproduction but reflected maturation of juveniles smaller than the plankton net mesh-size (i.e., "not visible" in our water column densities). Firstly, because we found the same size spectrum of individuals in both, the water column and the sediment traps meaning that the visually identifiable minimum size was consistent. Secondly, as continuous flux continued throughout the experiment, a life span $>4$ weeks must be assumed for a large portion of the population enclosed in the mesocosms because the experiment lasted 54 days. Planktonic foraminifers usually have short life-cycles (lunar, semi-lunar), (Bijma et al., 1990; Schiebel et al., 1997) thus it is unlikely that the continuous occurrence of foraminifers can be explained by a successive prolongation of life-cycles of (very) small juveniles enclosed at experiment start that successively sustained population densities and flux. A certain portion of the small juveniles would have needed to arrest development in order to provide for a continuous replenishment or flux of organisms over time. Thirdly, even if it was the case that small juveniles matured that were not caught with our net and contributed significantly to continuous flux, water column densities should have decreased over time but they remained fairly constant.

We found no relation between the abundance and succession of foraminifers and the $\mathrm{CO}_{2}$ concentrations in the mesocosms, i.e., Globigerinidae seemed to do equally well under the 
$\mathrm{CO}_{2}$ concentration range applied. However, our taxonomic resolution was low and we were not able to impose sizenormalized weight of specimen of the different species to infer on calcification. Thus, we cannot say anything on possible $\mathrm{CO}_{2}$ sensitivities on shell calcification or dissolution. But generally speaking, the present study concurs with previous work that showed no major vulnerability of growth rates of some large benthic foraminifer species to OA exposure in short term (up to 12 weeks) aquarium experiments (Vogel and Uthicke, 2012).

Despite more or less stable abundances of Globigerinidae in the water column in all mesocosms, flux to the sediment traps was reduced in the two high $\mathrm{CO}_{2}$ mesocosms during the post-bloom phase. Possibly, this reduced flux is in relation with the reduced POM flux described for the two high $\mathrm{CO}_{2}$ mesocosms as a consequence of delayed development of zooplankton (Stange et al., 2018; Algueró-Muñiz et al. submitted). Foraminifers might have become attached to sinking particles (POM) and transported downward that way. If so, a lower POM flux could also have lead to a lower flux of foraminifers. Similarly low flux, however, was also observed in one control mesocosm. Thus, we cannot be sure to what extent reduced POM flux or any other unknown factors contributed to flux reduction. Interestingly though, the observed zooplankton developmental delay was not found for planktonic foraminifers. This is discussed as a possible consequence of the occurrence of a harmful algae bloom in the two high $\mathrm{CO}_{2}$ mesocosms (Algueró-Muñiz et al. submitted; Riebesell et al., unpublished). Apparently, planktonic foraminifers had different sensitivities against this bloom compared to the remaining micro- and mesozooplankton community.

With respect to planktonic Foraminifera, field and laboratory observations on their response to $\mathrm{OA}$ provide an inconclusive picture, ranging from evidence for impaired calcification and growth to no reaction. The same applies to benthic foraminifera, where some taxa have even shown positive response to OA. As a result, no prediction of the effect of $\mathrm{OA}$ on planktonic foraminifera can be made on ecosystem level and new data are required particularly from field experiments.

\subsubsection{Conclusion}

Mesocosms cannot provide optimal living conditions for migrating zooplankton. This can bias specific response patterns especially those that are closely connected with species life cycles and migration patterns. Notably, in our study, this applied to the flux of planktonic Foraminifera. But this is a general problem true for each of the mesocosms, meaning a bias occurs consistently. Thus, differences that can be found between different treatment levels should still inform of possible treatment effects.

The present study did not reveal any statistically proven $\mathrm{CO}_{2}$-related trends on community level with respect to the abundance, succession and flux of planktonic Foraminifera and thecosome pteropods. In case of pteropods and heteropods, their occurrence in the mesocosms was too short to allow for any sound conclusion. With respect to foraminifers, the low taxonomic resolution and methodological constraints in our study did not allow for more detailed analyses of possible OA effects on individual species (e.g., calcification, carbon/carbonate flux), and the resulting difficulty to adequately connect their development in the water column in relation to their different life cycles with the observed flux to the sediment traps. Flux in the two high $\mathrm{CO}_{2}$ mesocosms could have been impacted by reduced POM flux that was in connection with $\mathrm{CO}_{2}$ concentrations. But this conclusion conflicts with also reduced flux in one control mesocosm where POM flux was not reduced (Stange et al., 2018). Future studies looking at community-level response of planktonic foraminifers should include species-level identification and biomass/calcite mass determination to allow for more in-depth investigation of possible OA effects. This can only be done, however, if a substantially higher amount of time can be invested.

\section{AUTHOR CONTRIBUTIONS}

SL, PS, and UR conceived, designed, and performed the experiment. SL analyzed the data. SL with input from all co-authors wrote the paper.

\section{FUNDING}

This project was funded by the German Federal Ministry of Education and Research (BMBF) in the framework of the coordinated project BIOACID-Biological Impacts of Ocean Acidification, phase 2 (FKZ 03F06550). UR received additional funding from the Leibniz Award 2012 by the German Research Foundation (DFG).

\section{ACKNOWLEDGMENTS}

We would like to thank the Oceanic Platform of the Canary Islands (Plataforma Oceánica de Canarias, PLOCAN) for their kind hospitality and great logistic support. We also gratefully acknowledge the captain and crew of RV Hesperides for deploying and recovering the mesocosms (cruise 29HE20140924), and RV Poseidon for transporting the mesocosms and support in testing the deep water collector during cruise POS463.

Many thanks are due to Isabel Dörner for her invaluable help with checking sediment trap samples for pteropods and foraminifers on site. We are also thankful to Dr. Scarlett Sett and Kaden Griffith who helped counting pelagic calcifiers in the zooplankton net and sediment-trap samples back home. Dr. Nina Keul is acknowledged for identification of foraminifer species. Dr. Lennart Bach provided carbonate system data. 


\section{REFERENCES}

Almogi-Labin, A., Hemleben, C., and Deuser, W. (1988). Seasonal variation in the flux of euthecosomatous pteropods collected in a deep sediment trap in the sargossa sea. Deep Sea Res. Part I Oceanogr. Res. Pap. 35, 441-464.

Arístegui, J., Hérnandez-Léon, S., Montero, F., and Gómez, M. (2001). The seasonal planktonic cycle in coastal waters of the canary islands. Sci. Mar. 65, 51-58.

Arístegui, J., Tett, P., Hernandez-Guerra, A., Basterretxea, G., Montero, M., Wild, K., et al. (1997). The influence of island-generated eddies on chlorophyll distribution:a study of mesoscale variation around gran canaria. Deep Sea Res. I 44, 71-96.

Bach, L. T., Taucher, J., Boxhammer, T., Ludwig, A., The Kristineberg KOSMOS Consortium, Achterberg, EP, et al. (2016). Influence of ocean acidification on a natural winter-to-summer plankton succession: First insights from a long-term mesocosm study draw attention to periods of low nutrient concentrations. PLoS ONE 11:e0159068. doi: 10.1371/journal.pone.01 59068

Bathmann, U., Noji, T., and von Bodungen, B. (1991). Sedimentation of pteropods in the norwegian sea in autumn. Deep Sea Res. 38, 1341-1360.

Bé, A., and Gilmer, R. (1977). Oceanic Micropalaeontology, volume 1, chapter A zoogeographic and taxonomic review of euthecosomatous Pteropoda. London: Academic Press, 773-808.

Bednaršek, N., Možina, J., Vogt, M., O’Brien, C., and Tarling, G. (2012a). The global distribution of pteropods and their contribution to carbonate and carbon biomass in the modern ocean. Earth Syst. Sci. Data 4, 167-186. doi: 10.5194/essd-4-167-2012

Bednaršek, N., Tarling, G., Bakker, D., Fielding, S., and Feely, R. (2014). Dissolution dominating calcification process in polar pteropods close to the point of aragonite undersaturation. PLOS ONE 9:e109183. doi: 10.1371/journal.pone.0109183

Bednaršek, N., Tarling, G., Bakker, D., Fielding, S., Jones, E., Venables, H., et al. (2012b). Extensive dissolution of live pteropods in the southern ocean. Nat. Geosci. 5, 881-885. doi: 10.1038/ngeo1635

Beer, C., Schiebel, R., and Wilson, P. (2010). Testing planktic foraminiferal shell weight as a surface water $\left[\mathrm{CO}^{2-}\right]$ proxy using plankton net samples. Geology 38, 103-106. doi: 10.1130/G30150.1

Bentov, S., Brownlee, C., and Erez, J. (2009). The role of seawater endocytosis in the biomineralization process in calcareous foraminifera. Proc. Natl. Acad. Sci. U.S.A. 106, 21500-21504. doi: 10.1073/pnas.0906636106

Berner, R., and Honjo, S. (1981). Pelagic sedimentation of aragonite: its geochemical significance. Science 211, 940-942.

Bijma, J., Erez, J., and Hembleben, C. (1990). Lunar and semi-lunar reproductive cycles in some spinose planktonic foraminifers. J. Foraminifer. Res. 20, 117-127.

Boxhammer, T., Bach, LT, Czerny, J., and Riebesell, U. (2015). Technical note: Sampling and processing of mesocosm sediment trap material for quantitative biogeochemical analysis. Biogeosciences 13, 2849-2858. doi: 10.5194/bg-13-2849-2016

Ciais, P., Sabine, C., Bala, G., Bopp, L., Brovkin, V., Canadell, J., et al. (2013). "Climate Change 2013: The Physical Science Basis," in Contribution of Working Group I to the Fifth Assessment Report of the Intergovernmental Panel on Climate Change," chapter Carbon and Other Biogeochemical Cycles. Cambridge: New York, NY: Cambridge University Press, 465-570.

Comeau, S., Gorsky, G., Alliouane, S., and Gattuso, J. (2010a). Larvae of the pteropod Cavolinia inflexa exposed to aragonite undersaturation are viable but shell-less. Mar. Biol. 157, 2341-2345. doi: 10.1007/s00227-010-1 493-6

Comeau, S., Jeffree, R., Teyssié, J., and Gattuso, J. (2010b). Response of the arctic pteropod Limacina helicina to projected future environmental conditions. PLoS ONE 5:e11362. doi: 10.1371/journal.pone.0011362

Davis, C., Rivest, E., Hill, T., Gaylord, B., Russell, A., and Sanford, E. (2017). Ocean acidification compromises a planktic calcifier with implications for global carbon cycling. Sci. Rep. 7:2225. doi: 10.1038/s41598-01701530-9

de Moel, H., Ganssen, G., Peeters, F., Jung, S., Kroon, D., Brummer, G., et al. (2009). Planktic foraminiferal shell thinning in the arabian sea due to anthropogenic ocean acidification? Biogeosciences 6, 1917-1925. doi: 10.5194/bg-6-19 17-2009 de Nooijer, L., Toyofuku, T., and Kitazato, H. (2009). Foraminifera promote calcification by elevating their intracellular ph. Proc. Natl. Acad. Sci. U.S.A. 8, 15374-15378. doi: 10.1073/pnas.0904306106

Dias, B., Hart, M., Smart, C., and Hall-Spencer, J. (2010). Modern seawater acidification: the response of foraminifera to high- $\mathrm{co} 2$ conditions in the mediterranean sea. J. Geol. Soc. 167, 843-846. doi: 10.1144/0016-76492010-050

Doney, S., Fabry, V., Feely, R., and Kleypas, J. (2009). Ocean acidification: The other $\mathrm{CO}_{2}$ problem. Ann. Rev. Mar. Sci. 1, 169-192. doi: 10.1146/annurev.marine.010908.163834

Dutkiewicz, S., Morris, J., Follows, M., Scott, J., Levitan, O., Dyhrm, S., et al. (2015). Impact of ocean acidification on the structure of future phytoplankton communities. Nat. Clim. Chang. 5, 1002-1006. doi: 10.1038/NCLIMATE2722

Erez, J., and Honjo, S. (1981). Comparison of isotopic composition of planktonic foraminifera in plankton tows, sediment-raps and sediments. Palaeogeogr. Palaeoclimatol. Palaeoecol. 33, 129-156.

Fabry, V., Seibel, B., Feely, R., and Orr, J. (2008). Impacts of ocean acidification on marine fauna and ecosystem processes. ICES J. Mar. Sci. 65, 414-432. doi: 10.1093/icesjms/fsn048

Feely, R., Sabine, C., Lee, K., Berelson, W., Kleypas, J., Fabry, V., et al. (2004). Impact of anthropogenic $\mathrm{co} 2$ on the caco3 system in the oceans. Science 305, 362-366. doi: 10.1126/science.1097329

Fischer, G., Donner, B., Ratmeyer, V., Davenport, R., and Wefer, G. (1996). Distinct year-to-year particle flux variations off cape blanc during 1988-1991: Relation to delta18o-deduced sea-surface temperatures and trade winds. J. Mar. Res. 54, 73-98.

Gonzalez-Mora, B., Sierro, F., and Flores, J. (2008). Controls of shell calcification in planktonic foraminifers. Quat. Sci. Rev. 27, 956-961. doi: 10.1016/j.quascirev.2008.01.008

Guinotte, J., and Fabry, V. (2008). Ocean acidification and its potential effects on marine ecosystems. Ann. N. Y. Acad. Sci. 1134, 320-342. doi: 10.1196/annals. 1439.013

Hammill, E., Johnson, E., Atwood, T., Harianto, J., Hinchliffe, C., Calosi, P., et al. (2017). Ocean acidification alters zooplankton communities and increases topdown pressure of a cubozoan predator. Glob. Chang. Biol. 24, e128-e138. doi: $10.1111 /$ gcb. 13849

Hemleben, C., Spindler, M., and Anderson, O., (eds.). (1989). Modern planktonic Foraminifera. Berlin: Springer-Verlag.

Howes, E., Bednaršek, N., Büdenbender, J., Comeau, S., Doubleday, A., Gallager, S., et al. (2014). Sink and swim: a status review of thecosome pteropod culture techniques. J. Plankton Res. 36, 299-315. doi: 10.1093/plankt/fbu002

Hull, P., Osborn, K., Norris, R., and Robison, B. (2011). Seasonality and depth distribution of a mesopelagic foraminifer, Hastigerinella digitata, in monterey bay, California. Limnol. Oceanogra. 56, 562-576. doi: $10.4319 /$ lo.2011.56.2.0562

Keul, N., Langer, G., Nooijer, L., and Bijma, J. (2013). Effect of ocean acidification on the benthic foraminifera Ammonia sp. is caused by a decrease in carbonate ion concentration. Biogeosciences 10, 6185-6198. doi: 10.5194/bg-10-61 85-2013

Kroeker, K., Kordas, R., Crim, R., Hendriks, I., Ramajo, L., Singh, G., et al. (2013). Impacts of ocean acidification on marine organisms: quantifying sensitivities and interaction with warming. Glob. Chang. Biol. 19, 1884-1896. doi: $10.1111 /$ gcb.12179

Kroeker, K., Kordas, R., Crim, R., and Singh, G. (2010). Meta-analysis reveals negative yet variable effects of ocean acidification on marine organisms. Ecol. Lett. 13, 1419-1434. doi: 10.1111/j.1461-0248.2010.01518.x

Lalli, C., and Gilmer, R. (1989). Pelagic Snails: The Biology of Holoplanktonic Gastropod Molluscs. Stanford, CA: Stanford University Press.

Le Quéré, C., Moriarty, R., Andrew, R., Peters, G., Ciais, P., Friedlingstein, P., et al. (2015). Global carbon budget 2014. Earth Syst. Sci. Data 7, 47-85 doi: 10.5194/essd-7-47-2015

Lischka, S., Büdenbender, J., Boxhammer, T., and Riebesell, U. (2011) Impact of ocean acidification and elevated temperatures on early juveniles of the polar shelled pteropod Limacina helicina: mortality, shell degradation, and shell growth. Biogeosciences 8, 919-932. doi: 10.5194/bg-8-9 19-2011

Lombard, F., da Rocha, R., Bijma, J., and Gattuso, J.-P. (2010). Effect of carbonate ion concentration and irradiance on calcification in planktonic foraminifera. Biogeosciences 7, 247-255. doi: 10.5194/bg-7-247-2010 
Manno, C., Morata, N., and Bellerby, R. (2012). Effect of ocean acidification and temperature increase on the planktonic foraminifer Neogloboquadrina pachyderma (sinistral). Polar Biol. 35, 1311-1319. doi: 10.1007/s00300-012-1174-7

McIntyre-Wressnig, A., Bernhard, J., McCorkle, D., and Hallock, P. (2013). Non-lethal effects of ocean acidification on the symbiontbearing benthic foraminifer Amphistegina gibbosa. Mar. Ecol. Prog. Ser. 472:45-60. doi: 10.3354/meps09918

Moy, A., Howard, W., Bray, S., and Trull, T. (2009). Reduced calcification in modern southern ocean planktonic foraminifera. Nat. Geosci. 2, 276-280. doi: $10.1038 /$ ngeo460

Mucci, A. (1983). The solubility of calcite and aragonite in seawater at various salinities, temperatures, and one atmosphere total pressure. Am. J. Sci. 283, 780-799.

Neuer, S., Cianca, A., Helmke, P., Freudenthal, T., Davenport, R., Meggers, H., et al. (2007). Biogeochemistry and hydrography in the eastern subtropical north atlantic gyre. results from the european time-series station estoc. Prog. Oceanogra. 72, 1-29. doi: 10.1016/j.pocean.2006.08.001

Niehoff, B., Schmithüsen, T., Knüppel, N., Daase, M., Czerny, J., and Boxhammer, T. (2013). Mesozooplankton community development at elevated $\mathrm{CO}_{2}$ concentrations: results from a mesocosm experiment in an arctic fjord. Biogeosciences 10, 1391-1406. doi: 10.5194/bg-10-1391-2013

Paul, A., Bach, L., Schulz, K., Boxhammer, T., Czerny, J., Achterberg, E., et al. (2015). Effect of elevated $\mathrm{CO}_{2}$ on organic matter pools and fluxes in a summer, post spring-bloom baltic sea plankton community. Biogeosciences 12 , 6181-6203. doi: 10.5194/bg-12-6181-2015

Prazeres, M., Uthicke, S., and Pandolfi, J. (2018). Ocean acidification induces biochemical and morphological changes in the calcification process of large benthic foraminifera. Proc. R. Soc. B. 282, 20142782. doi: $10.1098 /$ rspb.2014.2782

R Core Team (2013). R: A Language and Environment for Statistical Computing. Vienna: R Foundation for Statistical Computing. ISBN 3-900051-07-0.

Rebotim, A., Voelker, A., Jonkers, L., Waniek, J., Meggers, H., Schiebel, R., et al. (2017). Factors controlling the depth habitat of planktonic foraminifera in the subtropical eastern north atlantic. Biogeosciences 14, 827-859. doi: 10.5194/bg-14-827-2017

Rhein, M., Rintoul, S., Aoki, S., Campos, E., Chambers, D., Feely, R., et al. (2013). chapter Observations: Ocean, Climate Change 2013: The Physical Science Basis. Contribution of Working Group I to the Fifth Assessment Report of the Intergovernmental Panel on Climate Change. Cambridge, UK and New York, NY: Cambridge University Press, 255-315.

Riebesell, U., Bach, L., Bellerby, R., Bermudez Monsalve, R., Czerny, J., Larsen, A., et al. (2017). Competitive fitness of a predominant pelagic calcifier impaired by ocean acidification. Nat. Geosci. 10, 19-23. doi: 10.1038/ngeo2854

Riebesell, U., Czerny, J., von Bröckel, K., Boxhammer, T., Büdenbender, J., Deckelnick, M., et al. (2013). Technical note: A mobile sea-going mesocosm system - new opportunities for ocean change research. Biogeosciences 10, 1835-1847. doi: 10.5194/bg-10-1835-2013

Sala, M., Aparicio, F., Balagué, V., Boras, J., Borrull, E., Cardelús, C., et al. (2016). Contrasting effects of ocean acidification on the microbial food web under different trophic conditions. ICES J. Mar. Sci. 73, 670-679. doi: 10.1093/icesjms/fsv130

Sangra, P., Pascual, A., Rodríguez-Santana, A., Machín, F., Mason, E., McWilliams, J., et al. (2009). The canary eddy corridor: A major pathway for long-lived eddies in the subtropical north atlantic. Deep Sea Res. I 56, 2100-2114. doi: 10.1016/j.dsr.2009.08.008

Schiebel, R. (2002). Planktic foraminiferal sedimentation and the marine calcite budget. Glob. Biogeochem. Cycles 16:1065. doi: 10.1029/2001GB001459

Schiebel, R., Bijma, J., and Hemleben, C. (1997). Population dynamics of the planktic foraminifer Globigerina bulloides from the eastern north atlantic. Deep Sea Res. I 44, 1701-1713.
Schiebel, R., and Hemleben, C. (2000). Interannual variability of planktic foraminiferal populations and test flux in the eastern north atlantic ocean (jgofs). Deep Sea Res. Part II Top. Stud. Oceanogr. 47, 1809-1852. doi: 10.1016/S0967-0645(00)00008-4

Schmidt, C., Kucera, M., and Uthicke, S. (2014). Combined effects of warming and ocean acidification on coral reef foraminifera Marginopora vertebralis and Heterostegina depressa. Coral Reefs 33, 805-818. doi: 10.1007/s00338-014-1151-4

Stange, P., Taucher, J., Bach, L., Algueró-Muñiz, M., Horn, H., Krebs, L., et al. (2018). Ocean acidification-induced restructuring of the plankton food web can influence the degradation of sinking particles. Front. Mar. Sci. 5:140. doi: $10.3389 /$ fmars.2018.00140

Stumpp, M., Hu, M., Melzner, F., Gutowska, M., Dorey, N., Himmerkus, N., et al. (2012). Acidified seawater impacts sea urchin larvae ph regulatory systems relevant for calcification. Proc. Natl. Acad. Sci. U.S.A. 109, 18192-18197. doi: 10.1073/pnas.1209174109

Taucher, J., Bach, LT, Boxhammer, T., Nauendorf, A., The Gran Canaria KOSMOS Consortium, Achterberg, EP, et al. (2017). Influence of ocean acidification and deep water upwelling on oligotrophic plankton communities in the subtropical north atlantic: Insights from an in situ mesocosm study. Front. Mar. Sci. 4:85. doi: 10.3389/fmars.2017.00085

Thabet, A., Maas, A., Lawson, G., and Tarrant, A. (2015). Life cycle and early development of the thecosomatous pteropod Limacina retroversa in the gulf of maine, including the effect of elevated co2 levels. Mar. Biol. 162, 2235-2249. doi: 10.1007/s00227-015-2754-1

Tsurumi, M., Mackas, D., Whitney, A., DiBacco, C., Galbraith, M., and Wong, C. (2005). Pteropods, eddies, carbon flux, and climate variability in the alaska gyre. Deep Sea Res. Part II 52, 1037-1052. doi: 10.1016/j.dsr2.2005. 02.005

Uthicke, S., Momigliano, P., and Fabricius, K. (2013). High risk of extinction of benthic foraminifera in this century due to ocean acidification. Sci. Rep. 3:1796. doi: 10.1038/srep01769

Vogel, N., and Uthicke, S. (2012). Calcification and photobiology in symbiontbearing benthic foraminifera and responses to a high $\mathrm{co} 2$ environment. J. Exp. Mar. Biol. Ecol. 424-425:15-24. doi: 10.1016/j.jembe.2012. 05.008

Weinkauf, M., Kunze, J., Waniek, J., and Kucera, M. (2016). Seasonal variation in shell calcification of planktonic foraminifera in the ne atlantic reveals species-specific response to temperature, productivity, and optimum growth conditions. PLOS ONE 11:e0148363. doi: 10.1371/journal.pone. 0148363

Wilke, I., Meggers, H., and Bickert, T. (2009). Depth habitats and seasonal distributions of recent planktic foraminifers in the canary islands region $\left(29^{\circ} \mathrm{n}\right)$ based on oxygen isotopes. Deep Sea Res. Part I Oceanogr. Res. Pap. 56, 89-106. doi: 10.1016/j.dsr.2008.08.001

Wittmann, A., and Pörtner, H. (2013). Sensitivities of extant animal taxa to ocean acidification. Nat. Clim. Chang. 3, 995-1001. doi: 10.1038/NCLIMATE1982

Zeebe, R., and Wolf-Gladrow, D. (2001). $\mathrm{CO}_{2}$ in Seawater: Equilibrium, Kinetics, Isotopes. (Amsterdam: Elsevier Science).

Conflict of Interest Statement: The authors declare that the research was conducted in the absence of any commercial or financial relationships that could be construed as a potential conflict of interest.

Copyright (c) 2018 Lischka, Stange and Riebesell. This is an open-access article distributed under the terms of the Creative Commons Attribution License (CC BY). The use, distribution or reproduction in other forums is permitted, provided the original author(s) and the copyright owner(s) are credited and that the original publication in this journal is cited, in accordance with accepted academic practice. No use, distribution or reproduction is permitted which does not comply with these terms. 